\title{
Persistent hyperinsulinemic neonatal hypoglycemia caused by focal nesidioblastosis. Preoperative diagnosis by pancreatic venous sampling
}

\author{
Maria Maniati-Christidis ${ }^{1}$, Fotini Psychou ${ }^{2}$, Claire Nihoul-Fekete ${ }^{3}$ \\ ${ }^{1,2}$ First Pediatric Department, Athens University Medical School, Athens, Greece, ${ }^{3}$ Hôpital Necker-Enfants Malades, \\ Paris, France
}

\begin{abstract}
A female infant with persistent hyperinsulinemic hypoglycemia is described. Persistent euglycemia could not be achieved by diazoxide, somatostatin and frequent, low protein feeds. Preoperative localization of focal insulin hypersecretion by percutaneous pancreatic venous sampling allowed excision of only a small pancreatic portion which was followed by normalization of blood glucose levels.
\end{abstract}

Key words: persistent hyperinsulinemic hypoglycemia, focal nesidioblastosis, pancreatic venous sampling, diazoxide, somatostatin, pancreatectomy.

\section{INTRODUCTION}

Hyperinsulinism, although rare, is the most common cause (up to $50 \%$ ) of persistent infantile hypoglycemia $(\mathrm{PHHI})^{1}$. PHHI is usually associated with diffuse or focal nesidioblastosis and only rarely with pancreatic adenoma ${ }^{2}$. There are sporadic and familial forms of the disease with diverse molecular defects ${ }^{1-5}$. In the recessively inherited form, mutations have been demonstrated in the gene for the plasma membrane sulfonylurea receptor (SUR1) or its associated inwardly rectifying potassium channel (Kir6.2) of the beta cells ${ }^{1}$. In the dominantly inherited form, a mutation in the glucokinase gene has been identified ${ }^{3}$. The hy-

Address correspondence and requests for reprints to: M Maniati-Christidis, First Pediatric Department, Athens University Medical School, Aghia Sophia Children's Hospital, Goudi 115 27, Athens, Greece, Tel 210-7795538, Fax 210-7795538

Received 03-11-02, Revised 20-12-02, Accepted 30-12-02 perinsulinism-hyperammonemia syndrome is caused by mutations in the glutamate dehydrogenase gene $e^{4}$. Finally, in cases of focal PHHI, a specific loss of maternal alleles of the imprinted chromosome region $11 \mathrm{p} 15$ has been detected in the hyperplastic area of the pancreas ${ }^{2}$. The cellular hyperproliferation seems to be secondary to the expression of IGF-2 in the absence of $\mathrm{H} 19^{3}$.

We report a female infant presenting with hyperinsulinism due to focal adenomatous hyperplasia of the pancreas. Recognition of the focal lesion by percutaneous pancreatic venous sampling (PVS), preoperatively, permitted resection of the lesion and avoidance of blind, $95 \%$ pancreatectomy.

\section{CASE REPORT}

The patient, a female, was the first child of unrelated Greek parents. She was born at term after an 
uncomplicated pregnancy, by vaginal delivery. The birth weight was $4135 \mathrm{~g}$ and the length $47 \mathrm{~cm}$. She had plethora and hepatomegaly at birth. No cardiorespiratory resuscitation was required. Soon after delivery she had hypotonia and the blood glucose (BG) concentration was $0.5 \mathrm{mmol} / \mathrm{L}(10 \mathrm{mg} / \mathrm{dl})$. She was given an intravenous bolus of glucose followed by constant glucose infusion. Despite this regimen, hypoglycemic convulsions were observed in the ensuing 24 hours. The diagnosis of PHHI was made by demonstrating inappropriately raised levels of plasma insulin (Ins) in the absence of ketosis. Representative values were as follows: BG: $0.8 \mathrm{mmol} / \mathrm{L}(14 \mathrm{mg} / \mathrm{dl})$, Ins:205.2 pmol/ $\mathrm{L}(28,6 \mu \mathrm{U} / \mathrm{ml})$ and C-peptide: $1 \mathrm{nmol} / \mathrm{L}(3 \mathrm{ng} / \mathrm{ml})$. The insulin/glucose ratio (Ins/G) ranged from 0.27 to 2.9. Inborn errors of metabolism were excluded by appropriate testing (organic acids profile, carnitine, $\mathrm{NH}_{3}$ ). The values of growth hormone $(\mathrm{GH})$ during glucagon test $(100 \mu \mathrm{g} / \mathrm{kg} \mathrm{IM})$ carried out at the age of 2.5 months and while she was on diazoxide and somatostatin for about 2 months were normal (Table 1). Magnetic resonance imaging (MRI) and ultrasonography (US) of the pancreas were normal.

Insulin and C-peptide were determined by RIA using commercially available reagents (Insulin: SorinBiomedica, intra assay variation $6,6 \%$, inter assay variation 6,2\%, C-peptide: DSL 7000, intra assay variation $5,1 \%$ and intra assay variation $4,2 \%$ ) and glucose by glucose oxidase.

Her therapeutic regimen included IV glucose infusion, low protein feeds (daily protein intake of 2$2.5 \mathrm{~g} / \mathrm{kg} /$ day), diazoxide up to $15 \mathrm{mg} / \mathrm{kg} / 24 \mathrm{~h}$ and somatostatin $(10 \mu \mathrm{g} / \mathrm{kg} / \mathrm{day})$. This combination therapy gave satisfactory glycemia most of the time. Nevertheless, a precipitous drop of BG levels to $<1.1 \mathrm{mmol} / \mathrm{L}(20 \mathrm{mg} /$ dl) occurred once or twice daily, especially if the IV glucose infusion was interrupted owing to technical problems. Hence, it became evident that the patient could not be maintained on medical treatment alone

Table 1. Results of the glucagon test.

\begin{tabular}{cccc}
\hline \multicolumn{4}{c}{ Glucagon test } \\
\hline $\begin{array}{c}\text { Time } \\
(\mathbf{m i n})\end{array}$ & $\begin{array}{c}\text { BG } \\
(\mathbf{m m o l} / \mathbf{L})\end{array}$ & $\begin{array}{c}\text { Ins } \\
(\mathbf{p m o l} / \mathbf{L})\end{array}$ & $\begin{array}{c}\text { GH } \\
(\boldsymbol{\mu g} / \mathbf{L})\end{array}$ \\
\hline 0 & 3,94 & 69,6 & 17 \\
30 & 6,32 & 215,25 & 10 \\
60 & 7,7 & 63,14 & 13 \\
\hline
\end{tabular}

and surgery was considered necessary. In order to avoid blind pancreatectomy, a transdermal catheterization of pancreatic veins was performed at the age of 4.5 months (Hôpital Necker, France). Samples for Ins determination were obtained at 10 points ( 3 in the head, 3 in the tail of the pancreas and 1 in the portal vein, as indicated in Figure 1). Very high Ins values were obtained from a restricted area in the tail of the pancreas (Figure 1). During surgery, performed at the age of 4.5 months, foci with increased $\beta$ eta cell mass were found in the tail and part of the body of the pancreas. This area was subsequently excised. Histological examination of the excised pancreas documented focal nesidioblastosis. Following pancreatectomy, the patient has been normoglycemic without any medication. The Ins/G ratio has been in the range of 0.03 to 0.1 . She is now 3.5 years old and is developmentally normal. Her linear growth has improved post operatively. Specifically, her height SDS was $-0,5$ preoperatively and gradually reached the value of 0.8 at age 2 years (Figure 2).

\section{DISCUSSION}

Conservative management of PHHI consists of frequent, low protein feeds and inhibition of Ins secretion with diazoxide and/or octreotide, a long acting analog of somatostatin. Surgery is necessary for infants with hyperinsulinism who fail to be controlled by a conservative approach ${ }^{1}$. Currently, most pediatric surgeons recommend subtotal $(95 \%)$ pancreatectomy at the time of initial surgery since lesser resections are unlikely to control BG levels ${ }^{6}$. Subtotal pancreatectomy, however, is an unphysiologic and essentially blind procedure and, although more effective than partial surgery, carries an almost 50\% risk for later development of diabetes mellitus as well as exocrine pancreatic insufficiency ${ }^{7}$. Preoperative localization of a possible focal lesion would allow less extensive pancreatectomy. In our patient, preoperative localization of focal insulin hypersecretion allowed excision of only a small pancreatic portion.

Focal lesions are probably not so rare in pediatric patients as has generally been considered. In one series, $36 \%$ of pancreatic specimens obtained after blind pancreatectomy showed localized hypersecretion of Ins $^{2}$. Hence, it is important to recognize focal pancreatic dysfunction prior to or at surgery. It is generally assumed that focal nesidioblastosis is associated with 


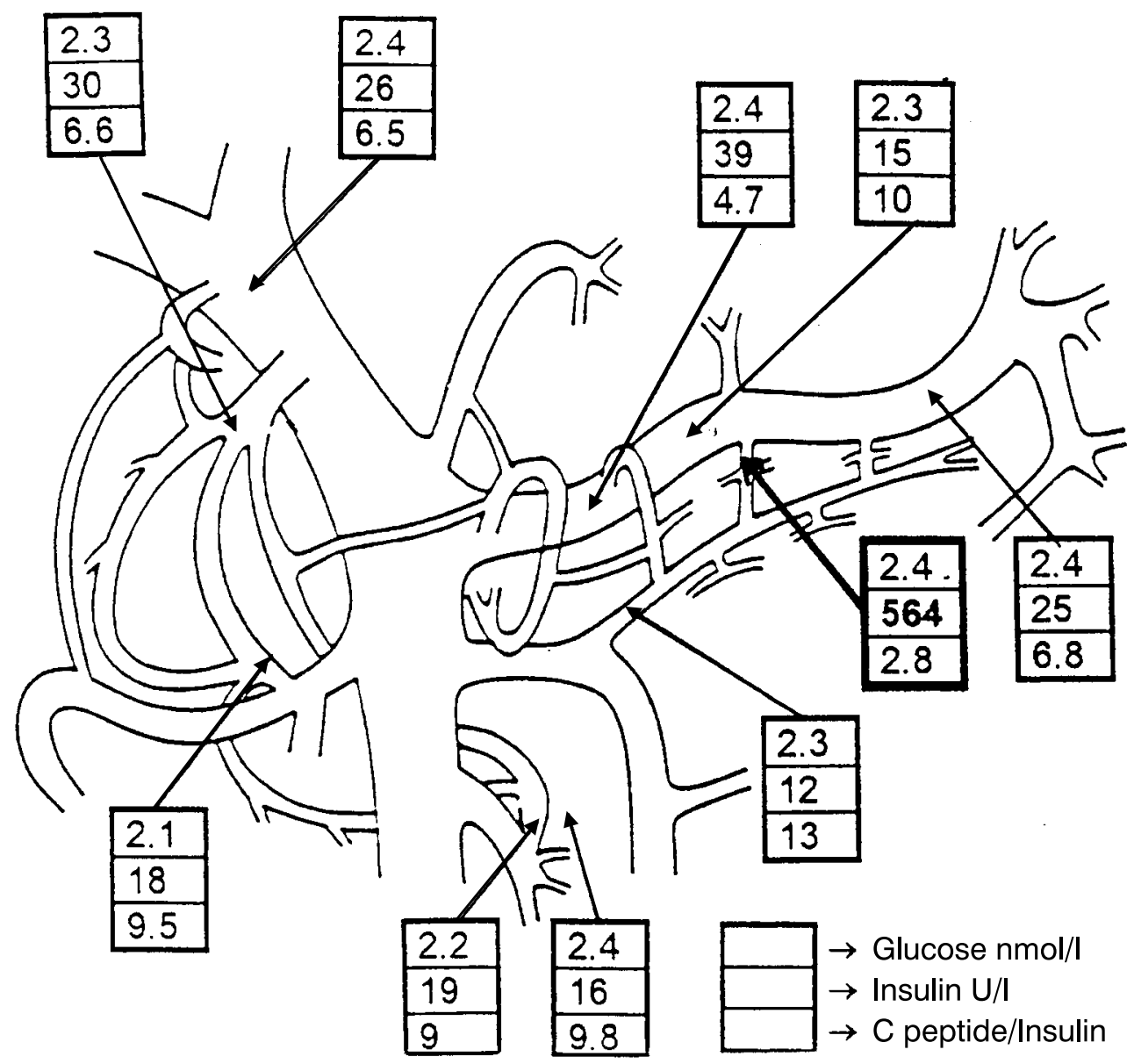

Figure 1. Glucose, insulin and C-peptide/Ins values after transdermal catheterization of the pancreatic veins.

less severe forms of congenital hyperinsulinism. However, certain patients with focal lesions, like ours, have severe disease.

The value of imaging to differentiate diffuse from focal pancreatic lesions related to adenomas has been questioned and different noninvasive diagnostic techniques have been proposed. Standard imaging studies like computed tomography (CT), MRI, US, and angiography correctly localize insulinomas in less than $50 \%$ of adult patients. The sensitivity of CT, MRI, US and angiography in localizing insulinomas is $24 \%$, $45 \%, 13 \%$ and $43 \%$, respectively. Intraoperative US scan detects $86-90 \%$ of insulinomas in adults but is very difficult in small infants and is not expected to be helpful in focal nesidioblastosis ${ }^{8}$. PVS has the advantage that it is not directly dependent on tumor size and has been recommended in adults before surgery when other tests fail to localize the tumor. It also appears as a valuable technique for the detection of fo- cal pancreatic lesions, whether adenoma or focal nesidioblastosis, in infants with hyperinsulinism. Nevertheless, PVS has the disadvantage of being an invasive and difficult procedure which requires experience and carries the risks of irradiation to the child and the radiologist ${ }^{9}$. Nowadays, intra-arterial calcium stimulation with right hepatic vein sampling for insulin gradients is considered a more sensitive preoperative test for localizing insulinomas in adults (sensitivity $88 \%)^{8}$. In children however seems to be less accurate than PVS in the evluation of PHHI ${ }^{10,11}$.

A final comment should be made concerning the linear growth pattern of our patient prior to and post surgery. Contrary to expectations, body length was at the lower centiles, despite hyperinsulinemia, and moved to higher percentiles following surgery. This must be attributed to the effect of somatostatin which, however, did not seem to be mediated through $\mathrm{GH}$ (normal base line GH values and post glucagon). Chil- 


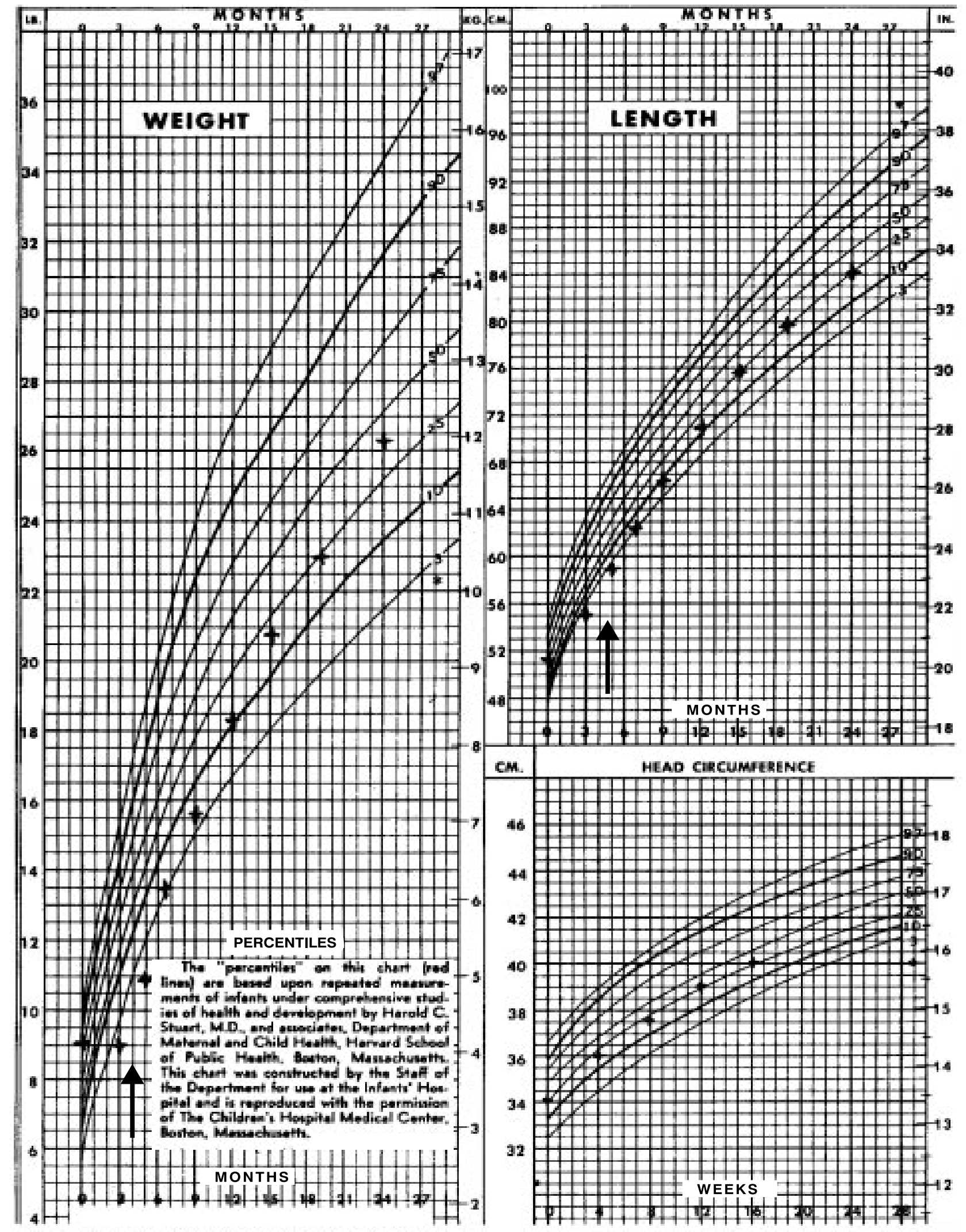

Figure 2. Growth data of the patient with focal nesidioblastosis pre- and post pancreatectomy. The arrow indicates the age at operation. 
dren in our center who take only diazoxide have normal linear growth; ${ }^{12}$ therefore, the impaired growth prior to surgery should not be attributed to diazoxide and is possibly related to somatostatin treatment.

\section{REFERENCES}

1. Aynsley-Green A, Dunne MJ, James RFL, Lindkey KJ, 1998 Ion and genes in persistent hyperinsulinaemic hypoglycemia in infancy: A commentary on the implications for tailoring treatment to disease pathogenesis. J Ped Endocrinol Metab 11: 121-129.

2. DeLonlay P, Fournet JC, Rahier J, et al, 1997 Somatic deletion of the imprinted $11 \mathrm{p} 15$ region in sporadic persistent hyperinsulinemichypoglycemia of infancy is specific of focal adenomatous hyperplasia and endorses partial pancreatectomy. J Clin Invest 100: 802-807.

3. Sempoux C, Guiot Y, Rahier J, 2001 The focal form of persistent hyperinsulinemic hypoglycaemia of infancy. Diabetes 50: 182-183.

4. Glaser B, Kesavan P, Heyman M, et al, 1998 familial hyperinsulinism caused by an activating glucokinase mutation. N Engl J Med 338: 226-230.

5. Stanley CA, Lieu YK, Hsu BYL, et al, 1998 Hyperinsulinism and hyperammonemia in infants with regulatory mutations of the glutamate dehydrogenase gene. N Engl J
Med 338: 1352-1357.

6. Spitz L, Bhargava RK, Grant DB, Leonard JV, 1992 Surgical treatment of hyperinsulinaemic hypoglycemia in infancy and childhood. Arch Dis Child 67: 201-205.

7. Soliman AT, Alsallmi I, Darwish A, Asfour MG, 1996 Growth and endocrine function after near total pancreatectomy for hyperinsulinaemic hypoglycemia. Arch Dis Child 74: 379-385.

8. Brown CK, Bartlett DL, Doppman JL, et al, 1997 Intraarterial calcium stimulation and intraoperative ultrasonography in the localization and resection of insulinomas. Surgery 122: 1189-1193.

9. Brunelle F, Negre V, Barth MO, et al, 1989 Pancreatic venous samplings in infants and children with primary hyperinsulinism. Pediatr Radiol 19: 100-103.

10. Abernethy LJ, Davidson DC, Lamont GL, Shepherd RM, Dunne MJ, 1998 Intraarterial calcium stimulation test in the investigation of hyperinsulinaemic hypoglycemia. Arch Dis Child 78: 359-363.

11. Chigot V, De Lonlay P, Nassogne MC, et al, 2001 Pancreatic arterial calcium stimulation in the diagnosis and localization of persistent hyperinsulinemic hypoglycaemia of infancy. Pediatr Radiol 3: 650-655.

12. Dacou-Voutetakis C, Psychou F, Maniati-Christidis M, 1998 Persistent hyperinsulinemic hypoglycemia of infancy. Long term results. J Pediatr Endocrinol Metabol 11: 131-141. 